\title{
Endophthalmitis following pars plana vitrectomy for vitreous floaters
}

This article was published in the following Dove Press journal:

Clinical Ophthalmology

28 August 2014

Number of times this article has been viewed

\author{
Christopher R Henry \\ Stephen G Schwartz \\ Harry W Flynn Jr \\ Department of Ophthalmology, \\ Bascom Palmer Eye Institute, \\ University of Miami Miller School \\ of Medicine, Miami, FL, USA
}

\begin{abstract}
A case of Staphylococcus caprae endophthalmitis in a young patient following pars plana vitrectomy for symptomatic vitreous floaters is reported here. Recent literature suggests that there is an increasing trend of performing pars plana vitrectomy for symptomatic floaters. Although rare, the potential risk of endophthalmitis should be explicitly discussed with patients considering surgical intervention for vitreous floaters.

Keywords: endophthalmitis, pars plana vitrectomy, vitreous floaters, floaterectomy, posterior vitreous detachment

\section{Introduction}

Endophthalmitis is a rare but vision-threatening complication following pars plana vitrectomy (PPV) with an incidence of one case per 1,730 procedures in a recent prospective study. ${ }^{1}$ A case of Staphylococcus caprae endophthalmitis developing in a healthy young patient following PPV for symptomatic vitreous floaters is reported here.
\end{abstract}

\section{Case report}

A healthy 24-year-old female complained of a large floater in the right eye (OD) for 6 months, that interfered with her graduate studies. Best-corrected visual acuity was 20/30 OD and 20/20 in the left eye (OS). Spherical equivalent was -7.50 D OD and OS. Examination was normal except for a prominent posterior vitreous detachment OD and lattice degeneration OD and OS. Observation was advised, but the patient requested treatment. After obtaining informed consent, a 20-gauge three-port PPV was performed without intraoperative complications. Cryotherapy was administered posterior to sclerotomy sites and to areas of lattice degeneration. Air-fluid exchange was not performed. The superior sclerotomies were closed in an $\mathrm{X}$-type fashion and the inferotemporal sclerotomy was closed in a purse-string fashion using 7-0 vicryl sutures. The conjunctiva was reapproximated using 6-0 plain gut sutures. Subconjunctival vancomycin $(25 \mathrm{mg} / 0.5 \mathrm{~mL})$ and dexamethasone $(2 \mathrm{mg} / 0.5 \mathrm{~mL})$ were injected.

On postoperative day 1 , uncorrected visual acuity OD was 4/200; intraocular pressure was $13 \mathrm{mmHg}$. Anterior segment examination revealed no eyelid edema, mild conjunctival injection, and 1+ aqueous cell with no posterior synechiae, hypopyon, or fibrin. Fundus examination showed mild vitreous cells with vascular sheathing and perivascular hemorrhages (Figure 1A). Spectral domain optical coherence tomography revealed retinal thickening and irregular intraretinal precipitates (Figure 1B). Fluorescein angiography demonstrated areas of blockage corresponding
Correspondence: Christopher R Henry Bascom Palmer Eye Institute, $900 \mathrm{NW}$ 17th Street, Miami, FL 33I36, USA

Tel +l 3053266000

Email chenry2@med.miami.edu 

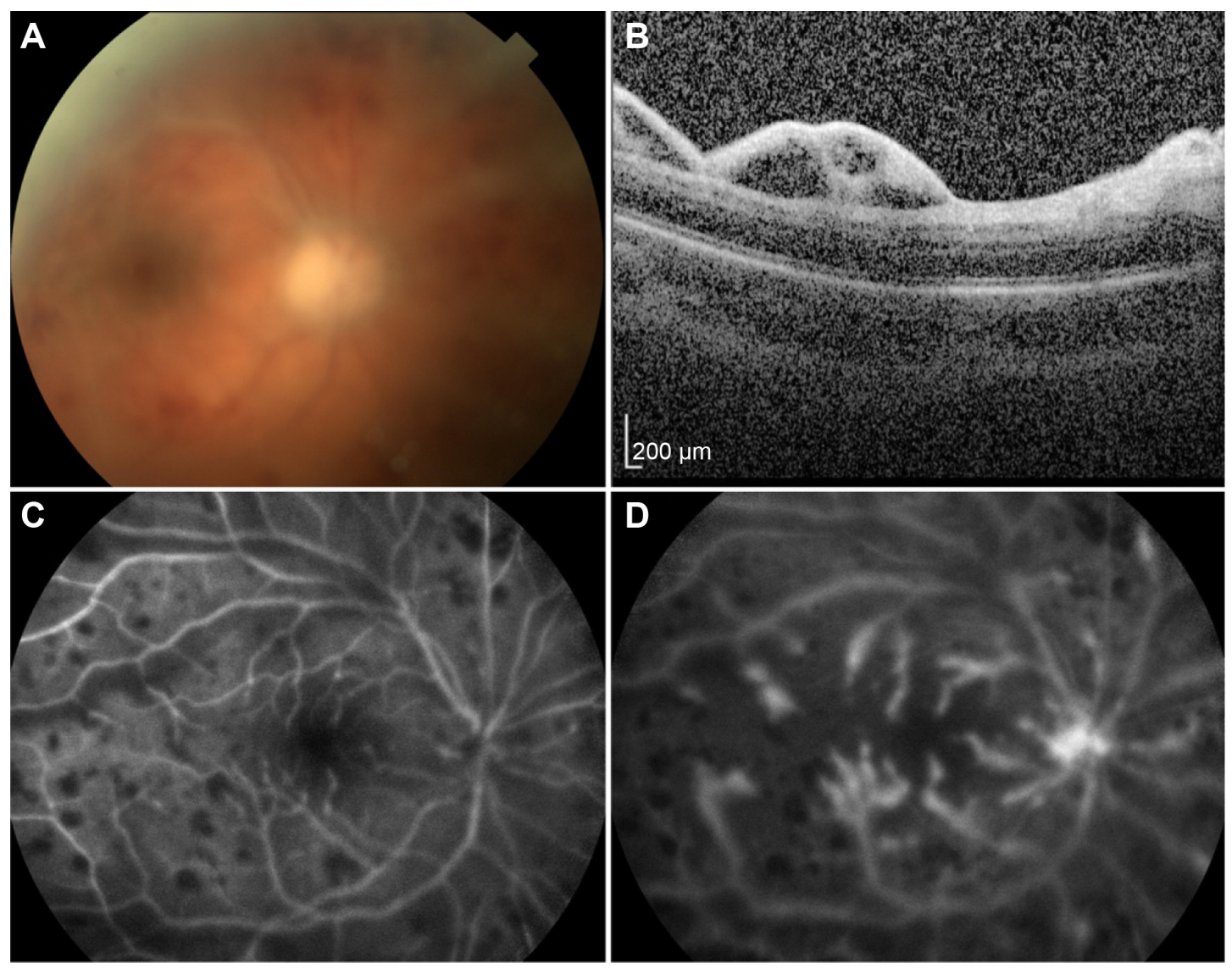

Figure I Postoperative day I appearance.

Notes: (A) Fundus photography, right eye, demonstrating mildly hazy media with vascular sheathing and perivascular hemorrhages. (B) Spectral domain optical coherence tomography, right eye, demonstrating retinal thickening and irregular intraretinal precipitates. (C) Early-phase fluorescein angiography, right eye, demonstrating areas of blockage corresponding to areas of perivascular hemorrhage. (D) Late phase fluorescein angiography, right eye, revealing leakage from retinal vessels and from the optic disc.

to the intraretinal hemorrhages and leakage from retinal vessels and from the optic disc (Figure $1 \mathrm{C}$ and D). Although the diagnosis of endophthalmitis was considered, it was felt that a toxic reaction to subconjunctival injections or retinal vascular occlusion were more likely based on the lack of severe intraocular inflammation and absence of fibrin or hypopyon. The patient was treated conservatively with topical ciprofloxacin $0.3 \%$ four times daily, prednisolone acetate $1 \%$ four times daily, and cyclopentolate $1 \%$ twice daily. The patient returned the following morning with worsened visual loss, pain, and eyelid swelling. Visual acuity was light perception and a relative afferent pupillary defect was noted. Intraocular pressure was $17 \mathrm{mmHg}$. Fibrin across the pupil and a $2 \mathrm{~mm}$ hypopyon in the anterior chamber were present. Fundus examination showed increased vitreous cavity inflammation. B-scan echography demonstrated an opacified vitreous skirt and shallow choroidal detachment. The patient was diagnosed with endophthalmitis and underwent emergent vitreous tap and injection with intravitreal vancomycin $(1 \mathrm{mg} / 0.1 \mathrm{~mL})$, ceftazidime
(2.25 mg/0.1 mL), and dexamethasone $(0.4 \mathrm{mg} / 0.1 \mathrm{~mL})$. Subconjunctival vancomycin $(50 \mathrm{mg} / 0.5 \mathrm{~mL})$ and ceftazidime $(50 \mathrm{mg} / 0.5 \mathrm{~mL})$ were administered. Oral moxifloxacin $400 \mathrm{mg}$ twice daily and topical besifloxacin $0.6 \%$ three times daily were added.

The eye responded well. Within days, the hypopyon diminished, the fibrin clot retracted (Figure 2A), and the choroidal detachment improved (Figure 2B). Vitreous cultures isolated $S$. caprae sensitive to vancomycin and levofloxacin. By postoperative month nine, best-corrected visual acuity improved to 20/80, partially limited by nuclear sclerosis. Fundus examination revealed a clear vitreous cavity with mottling of the retinal pigment epithelium (Figure 3A). Spectral domain optical coherence tomography revealed an irregular retinal surface but an intact ellipsoid layer (Figure 3B).

\section{Discussion}

Symptomatic floaters are common. In a recent study with an average participant age of 30 years, $76 \%$ reported symptomatic 

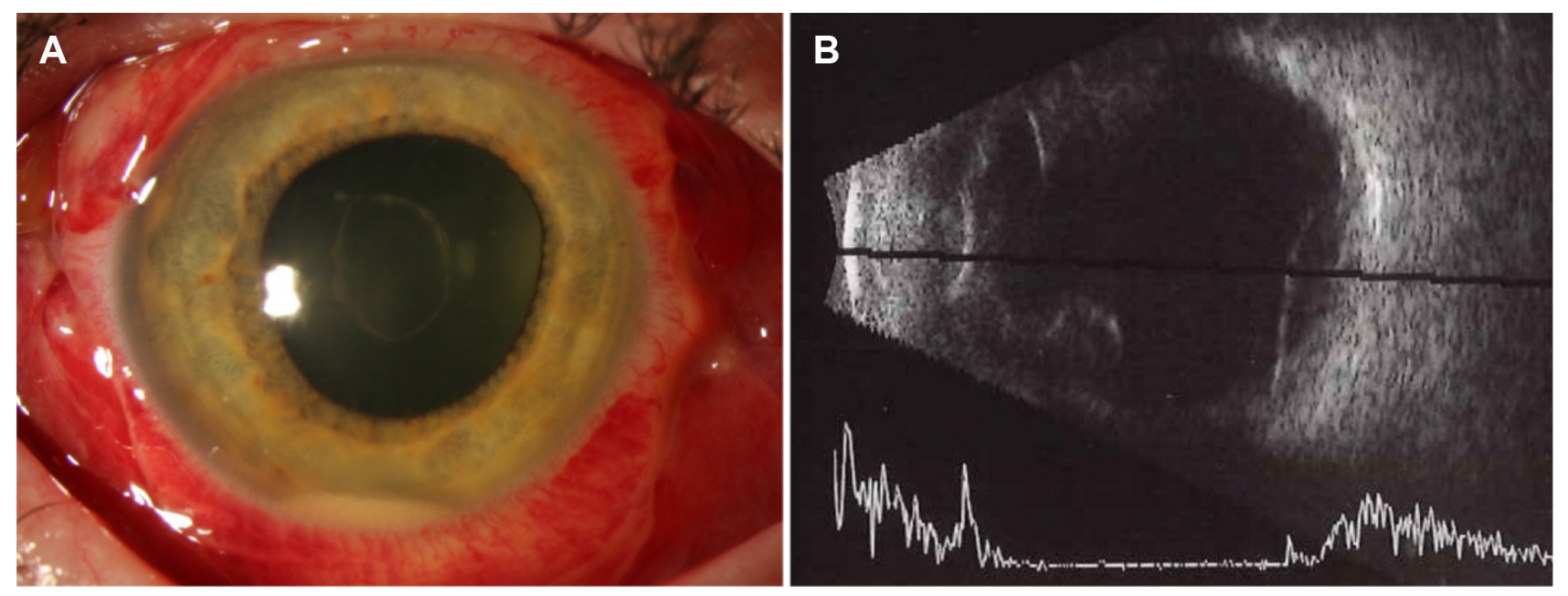

Figure 2 Postoperative day 4 appearance.

Notes: (A) Anterior segment photography, right eye, demonstrating improving hypopyon and retracting fibrin clot. (B) B-scan echography, right eye, demonstrating lowlying choroidal detachment.

floaters and 33\% reported noticeable impairment in vision from floaters. ${ }^{2}$ Among patients aged $70-79$ years, 35\% have evidence of a complete posterior vitreous detachment on echography and this number approaches $50 \%$ among patients aged 80 years and older. ${ }^{3}$ Vitreous floaters account for approximately $7 \%$ of new patient referrals to retina specialists. ${ }^{4}$

Floaters can cause considerable distress in certain patients. A utility analysis reported that patients were willing to trade away an average of 1.1 out of every 10 years of their remaining life to rid themselves of floaters, and were willing to take an $11 \%$ risk of death and a $7 \%$ risk of blindness to do so. ${ }^{5}$ Floaters can cause a reduction in contrast sensitivity and a demonstrable "floater scotoma" can be identified using spectral domain optical coherence tomography in some patients. ${ }^{6,7}$ Fortunately, most patients will accept observation as the symptoms are often temporary, opacities may gravitate out of the visual axis, and central opacities may move more anteriorly and out of focus. However, some patients may request definitive intervention despite surgical risks. ${ }^{8}$

Various treatments, such as neodymium:yttrium aluminum garnet vitreolysis and cataract extraction with deep anterior vitrectomy, have been reported. ${ }^{9,10}$ However, PPV is associated with the highest surgical success rates, with patient satisfaction rates ranging from $85 \%-94 \%$ and resolution of floaters on ophthalmoscopy in over 95\% of cases..$^{6,11-14}$ Using the 39-item National Eye Institute Visual Function Questionnaire, it has been reported that general vision, near activities, distance activities, mental health, and peripheral
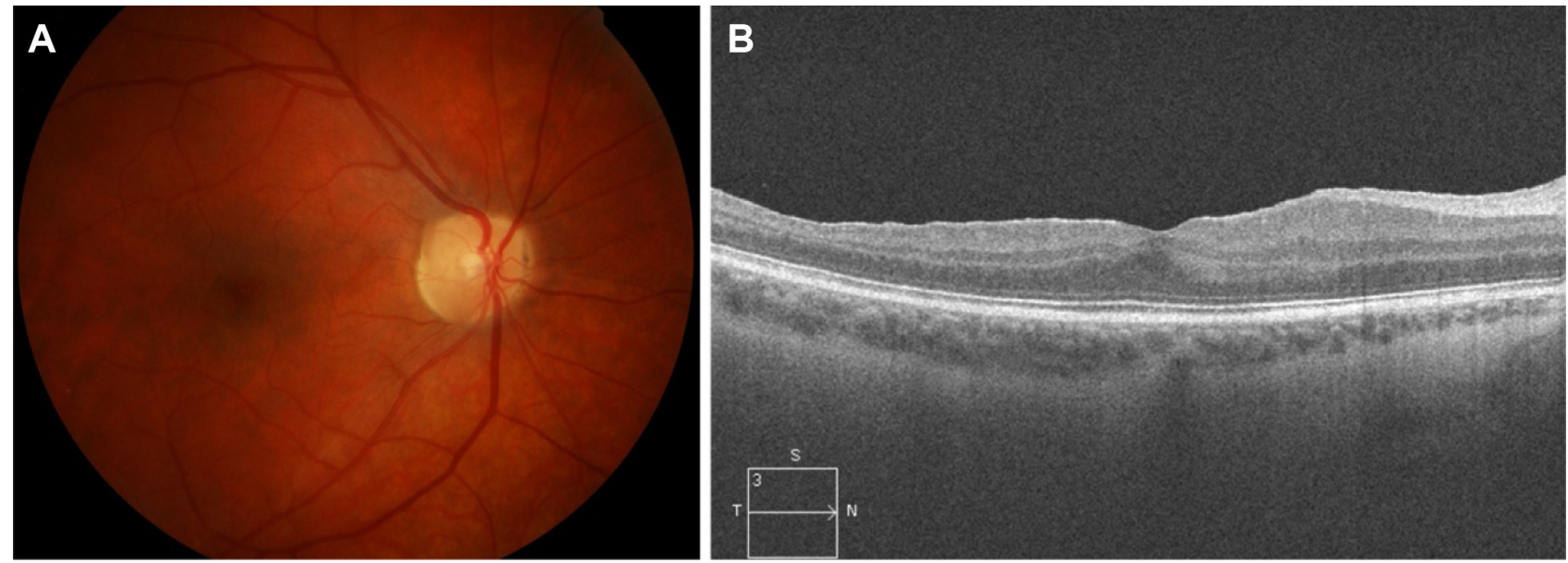

Figure 3 Postoperative month 9 appearance.

Notes: (A) Fundus photography, right eye, demonstrating clear media and mottling of the retinal pigment epithelium. (B) Spectral domain optical coherence tomography, right eye, demonstrating an irregular retinal surface but intact ellipsoid layer. 
vision are significantly improved in selected patients treated with PPV for floaters. ${ }^{15}$

There is an increasing trend towards PPV for symptomatic floaters, which is sometimes referred to as "floaterectomy". ${ }^{6,11-15}$ Unfortunately, while satisfaction rates are high, this treatment is not risk-free and large retrospective studies have reported rare but serious complications. De Nie et al retrospectively reviewed the results of 110 eyes undergoing 20-gauge or 23-gauge PPV for floaters and reported retinal detachment in 12 eyes $(10.9 \%)$, vitreous hemorrhage in $12(10.9 \%)$, cystoid macular edema in six (5.5\%), and visually significant cataract in $37 / 74$ phakic eyes $(50.0 \%) .{ }^{11}$ Schulz-Key et al reviewed 73 eyes undergoing primarily 20-gauge PPV for floaters and reported retinal detachment in five eyes $(6.8 \%)$, vitreous hemorrhage in seven $(9.6 \%)$, macular edema in four (5.5\%), and visually significant cataract in $23 / 38$ phakic eyes $(60.5 \%) .^{12}$

Two recent series suggest that some complications may be fewer with 25-gauge PPV. Mason et al reviewed 168 eyes undergoing sutureless 25-gauge PPV for floaters and reported 12 eyes $(7.1 \%)$ with retinal breaks, two with vitreous hemorrhage $(1.2 \%)$, one with cystoid macular edema $(0.6 \%)$, and no eyes with retinal detachment. Visually significant cataract developed in nine $(22.5 \%)$ of 40 phakic eyes. ${ }^{14}$ Sebag et al reviewed 60 eyes undergoing sutureless 25-gauge PPV for floaters and reported one eye $(1.7 \%)$ with macular pucker and no eyes with retinal breaks, vitreous hemorrhage, or retinal detachment. Visually significant cataract developed in eight $(23.5 \%)$ of 34 phakic eyes. $^{6}$

The case reported here does not represent the first case of endophthalmitis following PPV for vitreous floaters in the published literature. Park et al recently published two prospective, nationwide studies investigating the incidence, risk factors, clinical presentation, microbiology, management, and outcomes of patients developing endophthalmitis after PPV in the UK. ${ }^{1,16}$ In their series, 28 of 48,433 eyes undergoing PPV developed postoperative endophthalmitis. ${ }^{1}$ Two patients in their series developed endophthalmitis following PPV for vitreous opacities, both of which were caused by Gram-positive cocci. ${ }^{2}$ One patient regained a visual acuity of $6 / 9$ at 6 months following presentation with endophthalmitis; however, the other patient developed persistent cystoid macular edema and only recovered 6/96 vision.

Patients undergoing floaterectomy are often young, many are phakic, and nearly all have excellent preoperative best-corrected visual acuity. ${ }^{8}$ Endophthalmitis remains a rare, but potentially devastating complication for patients undergoing seemingly straightforward PPV for vitreous floaters and, in the authors' opinion, this risk should be explicitly addressed in the informed consent process of patients considering this intervention.

\section{Acknowledgments}

This research was funded in part by an unrestricted grant from Research to Prevent Blindness Inc., (New York, NY, USA) and the National Institutes of Health NEI Center Grant P30 EY014801.

\section{Disclosure}

SGS is a consultant for Bausch + Lomb and Santen, and is a speaker for ThromboGenics. HWF is a consultant for Santen. CRH reports no conflicts of interest in this work. The authors do not have any proprietary interests in the materials described in this article. This work has not been previously published or presented at a national meeting.

\section{References}

1. Park JC, Ramasamy B, Shaw S, Prasad S, Ling RH. A prospective and nationwide study investigating endophthalmitis following pars plana vitrectomy: incidence and risk factors. Br J Ophthalmol. 2014; 98(4):529-533.

2. Webb BF, Webb JR, Schroeder MC, North CS. Prevalence of vitreous floaters in a community sample of smartphone users. Int J Ophthalmol. 2013;6(3):402-405.

3. Weber-Krause B, Eckardt C. [Incidence of posterior vitreous detachment in the elderly]. Ophthalmologe. 1997;94(9):619-623. German.

4. Fijalkowsi N, Pershing S, Moshfeghi DM. The importance of keeping a broad differential in retina clinic: the spectrum of ophthalmic disease seen by retina specialists in a tertiary outpatient clinic setting. Ophthalmic Surg Lasers Imaging Retina. 2013;44(2):133-139.

5. Wagle AM, Lim WY, Yap TP, Neelam K, Au Eong HG. Utility values associated with vitreous floaters. Am J Ophthalmol. 2011;152(1): 60-65.

6. Sebag J, Yee KM, Wa CA, Huang LC, Sadun AA. Vitrectomy for floaters: prospective efficacy analysis and retrospective safety profile. Retina. 2014;34(6):1062-1068.

7. Schwartz SG, Flynn HW Jr, Fisher YL. "Floater scotoma" demonstrated on spectral-domain optical coherence tomography and caused by vitreous opacification. Ophthalmic Surg Lasers Imaging Retina. 2013;44(4): 415-418.

8. Henry CR, Smiddy WE, Flynn HW Jr. Pars plana vitrectomy for vitreous floaters: is there such a thing as minimally invasive vitreoretinal surgery? Retina. 2014;34(6):1043-1045.

9. Mossa F, Delaney YM, Rosen PH, Rahman R. Floaterectomy: combined phacoemulsification and deep anterior vitrectomy. J Cataract Refract Surg. 2002;28(4):589-592.

10. Delaney YM, Oyinloye A, Benjamin L. Nd:YAG vitreolysis and pars plana vitrectomy: surgical treatment for vitreous floaters. Eye (Lond). 2002;16(1):21-26.

11. De Nie KF, Crama N, Tilanus MA, Klevering BJ, Boon CJ. Pars plana vitrectomy for disturbing primary vitreous floaters: clinical outcome and patient satisfaction. Graefes Arch Clin Exp Ophthalmol. 2013; 251(5):1373-1382.

12. Schulz-Key S, Carlsson JO, Crafoord S. Longterm follow-up of pars plana vitrectomy for vitreous floaters: complications, outcomes, and patient satisfaction. Acta Ophthalmol. 2011;89(2):159-165. 
13. Tan HS, Mura M, Lesnik Oberstein SY, Bij1 HM. Safety of vitrectomy for floaters. Am J Ophthalmol. 2011;151(6):995-998.

14. Mason JO 3rd, Neimkin MG, Mason JO 4th, et al. Safety, efficacy, and quality of life following sutureless vitrectomy for symptomatic vitreous floaters. Retina. 2014;34(6):1055-1061.

15. Schiff WM, Chang S, Mandava N, Barile GR. Pars plana vitrectomy for persistent, visually significant vitreous opacities. Retina. 2000;20(6): 591-596.
16. Park JC, Ramasamy B, Shaw S, Ling RH, Prasad S. A prospective and nationwide study investigating endophthalmitis following pars plana vitrectomy: clinical presentation, microbiology, management, and outcome. Br J Ophthalmol. 2014;98(8):1080-1086.

\section{Publish your work in this journal}

Clinical Ophthalmology is an international, peer-reviewed journal covering all subspecialties within ophthalmology. Key topics include: Optometry; Visual science; Pharmacology and drug therapy in eye diseases; Basic Sciences; Primary and Secondary eye care; Patien Safety and Quality of Care Improvements. This journal is indexed on

Submit your manuscript here: http://www.dovepress.com/clinical-ophthalmology-journal

\section{Dovepress}

PubMed Central and CAS, and is the official journal of The Society of Clinical Ophthalmology (SCO). The manuscript management system is completely online and includes a very quick and fair peer-review system, which is all easy to use. Visit http://www.dovepress.com/ testimonials.php to read real quotes from published authors. 